\title{
Diffuse large B-cell lymphoma in a high human immunodeficiency virus (HIV) prevalence, low-resource setting
}

\begin{tabular}{|c|c|}
\hline \multicolumn{2}{|c|}{$\begin{array}{l}\text { Authors: } \\
\text { Pumza S. Magangane }{ }^{1,}{ }^{2} \\
\text { Zainab Mohamed } \\
\text { Richard Naidoo }\end{array}$} \\
\hline \multicolumn{2}{|c|}{$\begin{array}{l}\text { Affiliations: } \\
{ }^{1} \text { Division of Anatomical } \\
\text { Pathology, Department of } \\
\text { Pathology, University of } \\
\text { Cape Town, Cape Town, } \\
\text { South Africa }\end{array}$} \\
\hline \multicolumn{2}{|c|}{$\begin{array}{l}{ }^{2} \text { National Health Laboratory } \\
\text { Services, Cape Town, } \\
\text { South Africa }\end{array}$} \\
\hline \multicolumn{2}{|c|}{$\begin{array}{l}{ }^{3} \text { Department of Radiation } \\
\text { Oncology, University } \\
\text { of Cape Town, Cape } \\
\text { Town, South Africa }\end{array}$} \\
\hline \multicolumn{2}{|c|}{$\begin{array}{l}{ }^{4} \text { Groote Schuur Hospital, } \\
\text { Cape Town, South Africa }\end{array}$} \\
\hline \multicolumn{2}{|c|}{$\begin{array}{l}\text { Corresponding author: } \\
\text { Richard Naidoo, } \\
\text { richard.naidoo@uct.ac.za }\end{array}$} \\
\hline \multicolumn{2}{|c|}{$\begin{array}{l}\text { Dates: } \\
\text { Received: } 03 \text { Oct. } 2019 \\
\text { Accepted: } 10 \text { Dec. } 2019 \\
\text { Published: } 24 \text { Feb. } 2020\end{array}$} \\
\hline \multicolumn{2}{|c|}{$\begin{array}{l}\text { How to cite this article: } \\
\text { Magangane PS, Mohamed Z, } \\
\text { Naidoo R. Diffuse large B-cell } \\
\text { lymphoma in a high human } \\
\text { immunodeficiency virus (HIV) } \\
\text { prevalence, low-resource } \\
\text { setting. S. Afr. j. oncol. } \\
2020 ; 4(0), \text { a104. https://doi. } \\
\text { org/10.4102/sajo.v4i0.104 }\end{array}$} \\
\hline \multicolumn{2}{|c|}{$\begin{array}{l}\text { Copyright: } \\
\text { (C) 2020. The Authors. } \\
\text { Licensee: AOSIS. This wor } \\
\text { is licensed under the } \\
\text { Creative Commons } \\
\text { Attribution License. }\end{array}$} \\
\hline \multicolumn{2}{|l|}{ Read online: } \\
\hline 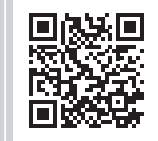 & $\begin{array}{l}\text { Scan this QR } \\
\text { code with your } \\
\text { smart phone or } \\
\text { mobile device } \\
\text { to read online. }\end{array}$ \\
\hline
\end{tabular}

Background: Diffuse large B-cell lymphoma (DLBCL) is a heterogeneous disease that includes a wide spectrum of lymphomas posing challenges in diagnosis and treatment. Diffuse large B-cell lymphoma is the most common lymphoma subtype occurring in older populations as well as in younger HIV-infected patients. Outcomes have improved with antiretroviral therapy and the use of rituximab; however, it remains poorly treated in resource-constrained countries.

Aim: This study aimed to determine differences in clinical features between HIV-negative and HIV-positive DLBCL cases by conducting a retrospective study

Setting: A tertiary hospital in Cape Town, South Africa.

Methods: We evaluated 263 DLBCL cases grouped according to HIV status over an 11-year period.

Results: The clinical features for HIV-negative and HIV-positive DLBCL cases were similar except for age of presentation and frequency of elevated lactate dehydrogenase (LDH). Several factors were prognostic for all DLBCL cases, including age of presentation, gender, stage, LDH and bone marrow involvement. In addition, extranodal site was also a prognostic indicator for the HIV-negative cohort.

Conclusion: Our study concluded that HIV-negative and HIV-positive DLBCL cases generally have similar clinicopathological and prognostic features.

Keywords: DLBCL; HIV infection; South Africa; oncology; treatment.

\section{Introduction}

Diffuse large B-cell lymphoma (DLBCL) constitutes 30\% of all Non-Hodgkin lymphoma (NHL) cases in developed countries with an even higher frequency in developing countries. ${ }^{1,2}$ Diffuse large B-cell lymphoma can occur at all ages but has a median age at diagnosis of 64 years. ${ }^{3}$ The disease is aggressive in nature and occurs at nodal or extranodal (EN) sites. ${ }^{3} \mathrm{Up}$ to $40 \%$ of DLBCL cases are EN with the gastrointestinal (GI) tract being the most common site. ${ }^{4,5}$ In 1993, the international prognostic index (IPI) was established as a prognostic predictor for NHL. ${ }^{6,7}$ The addition of the CD20 antibody, rituximab, during standard Cyclophosphamide, Doxorubicin, Vincristine, Prednisone (CHOP) chemotherapy has improved the 4-year overall survival rate by $10 \% .{ }^{8}$ With the use of rituximab, the revised National Comprehensive Cancer Network (NCCN) $\mathrm{IPI}^{9}$ is increasingly being used clinically. The newer prognostic systems consider the improvement in overall survival because of the use of rituximab. This ensures a more accurate differentiation between the risk groups. Rituximab-CHOP ( $\mathrm{RCHOP})$ is the international standard of care for the management of DLBCL; however, it is not freely available in resource-limited settings. The use of rituximab in human immunodeficiency virus (HIV)-positive patients has coincided with improved outcomes in this group of patients and is recommended..$^{10,11}$

Diffuse large B-cell lymphoma is the most common HIV-associated lymphoma, comprising about $50 \%$ of all lymphomas seen in this group. ${ }^{12,13}$ The introduction of Highly active antiretroviral therapy (HAART) has reduced the risk of acquiring $\mathrm{NHL}^{14}$ and improved the outcome of HIV-positive patients affected with DLBCL. ${ }^{11,15,16}$

The morphology of HIV-related DLBCL is similar to that seen in HIV-uninfected counterparts. ${ }^{17}$ The aim of this study was to compare the clinical features and survival of HIV-positive and HIVnegative DLBCL cases at a resource-limited, tertiary hospital in South Africa. 


\section{Materials and methods Case selection}

The study was a retrospective analysis of DLBCL patients diagnosed and treated at Groote Schuur Hospital (GSH) over a period of 11 years (01 January 2003-31 December 2013). An electronic search was conducted on the laboratory information system database of the Division of Anatomical Pathology, National Health Laboratory Service, using the Systemised Nomenclature of Medicine (snomed), Code: M-96803. The generated list was used to search for patient folders at the Department of Radiation Oncology, GSH. The snomed codes, M-95953, M-95913 and M-95903, were also used to search for additional cases.

\section{Folder selection}

Baseline demographic and clinical data were extracted, including treatment, response and survival. The following cases were excluded: those with no folder number, those with missing folders, absence of an HIV test result and lymphoma intermediate between Burkitt lymphoma (BL) and DLBCL. The following cases were included: 'sclerosing' DLBCL (four cases) and T-cell or histiocyte rich large B-cell lymphoma (10 cases).

\section{Treatment of diffuse large B-cell lymphoma patients}

The majority of DLBCL patients were treated using CHOP therapy without rituximab. Twelve of the HIV-negative patients from 2012 to 2013 were treated using RCHOP. These cases were excluded in the Kaplan-Meier calculations. Intrathecal chemotherapy was used in patients with risk factors for central nervous system (CNS) disease. Some patients in this study also received dose-reduced chemotherapy, palliative radiotherapy and involved field radiotherapy. HIV-negative cases with a poor response to $\mathrm{CHOP}$ or those who relapsed were considered for high-dose salvage chemotherapy and stem cell transplantation. All HIV-positive cases with refractory disease or relapse received palliative radiotherapy and/or chemotherapy. All HIVpositive patients received HAART either prior to or after lymphoma diagnosis. Rituximab became available for use at this institution from November 2013. Treatment response was assessed by computerized tomography (CT) scan using response evaluation criteria in solid tumors (RECIST) criteria. Positron emission tomography-computed tomography (PET-CT) was not routinely used for interim assessment of non-Hodgkin's lymphoma in HIV-positive patients and only used for the HIV-negative group in the last 2 years of the study period.

\section{Classification of lymphoma into nodal and extranodal}

We classified tumours as nodal and EN using criteria stated in the work of Møller et al. ${ }^{18}$ Lymphomas with clinically dominant lymph node involvement, as well as those presenting in the spleen or Waldeyer's ring, were classified as nodal lymphoma.
Patients were defined as having EN DLBCL when the disease, after the staging procedures, was confined to one or more EN sites and with no (or only minor) nodal involvement. Primary tumour sites were categorised into GI tract, breast, haematologic system (blood and bone marrow), genitourinary tract, head and neck, liver or pancreas, respiratory system, skeletal tissue, skin or soft tissue and thyroid.

\section{Statistical analysis}

The statistical analysis of the data was conducted using Stata 12 unless otherwise stated. Comparisons between numerical variables were conducted using an unpaired $t$-test. Categorical variables were compared using chi-square or Fischer's exact test. The linear regression analyses were completed using STATISTICA 12 with default settings. The overall survival was calculated from the date of first treatment to the date of death or last contact. Kaplan-Meier survival curves were drawn for overall survival times using GraphPad Prism 6.

\section{Ethical considerations}

The study was approved by the University of Cape Town Human Research Ethics Committee on 04 June 2010 (Reference number: HREC REF: 261/2010).

\section{Results}

\section{Baseline characteristics of human immunodeficiency virus-negative and -positive diffuse large B-cell lymphoma}

A total of 556 cases were diagnosed as DLBCL during 20032013 using the National Health Laboratory Service (NHLS) database; however, only 259 folders were located (Table 1). Patient age at diagnosis ranged from 13 years to 92 years, with a median of 52 years (Table 1). The majority of the located cases were HIV-negative (205/259) (Table 1). The HIV-positive cases had a statistically significant lower age at diagnosis with a median of 40 years, compared to 55 years for the HIV-negative cases $(p<0.0001)$ (Table 1$)$. There were only 219 cases with recorded gender, with females being the predominant gender (117 females vs. 102 males). This was observed for both HIV-negative and HIV-positive groups (Table 1). There were 192 and 200 cases with B-symptoms (fever, night sweats and weight loss) and bone marrow involvement (BMi) recorded, respectively. Equal proportions of HIV-negative and HIV-positive DLBCL cases presented with B-symptoms (35\% vs. $34.7 \%$ ) and BMi (42\% vs. $46 \%$ ).

There were 244 and 238 cases with Ann Arbor stage and performance status (PS) recorded, respectively (Table 1). Most of the HIV-negative cases were classified as stage II and stage IV (30.26\% and 40\%) (Table 1). In contrast, the majority of the cases in the HIV-positive group were classified as stage III and stage IV (44.90\% and $22.45 \%)$. Most cases were Eastern Cooperative Oncology Group (ECOG) PS 1 at presentation (44.96\%). This was observed for both the HIV-negative (45.45\%) and HIV-positive (43.1\%) cohorts. Lactate dehydrogenase levels were frequently elevated in 
TABLE 1: The clinical biological parameters of diffuse large B-cell lymphoma from human immunodeficiency virus-infected and -uninfected patients.

\begin{tabular}{|c|c|c|c|c|c|c|c|}
\hline \multirow[t]{2}{*}{ Variable } & \multicolumn{2}{|c|}{ All DLBCL } & \multicolumn{2}{|c|}{ HIV- DLBCL } & \multicolumn{2}{|c|}{ HIV+ DLBCL } & \multirow[t]{2}{*}{$p$} \\
\hline & $N$ & $\%$ & $N$ & $\%$ & $N$ & $\%$ & \\
\hline Number of patients & 259 & 100 & 205 & 79.15 & 54 & 20.85 & - \\
\hline Median age (range) & $52(13-92)$ & - & $55(13-92)$ & - & $40(14-72)$ & - & $<0.0001$ \\
\hline $\begin{array}{l}\text { Male gender } \\
N \text { (total) }\end{array}$ & $102(219) \dagger, \dagger$ & 46.60 & $79(166) \ddagger$ & 47.60 & $23(53) \ddagger$ & 43.20 & 0.5940 \\
\hline Ann Arbor stage (total) & 244 & - & 195 & - & 49 & - & 0.0570 \\
\hline I & 45 & 18.44 & 36 & 18.46 & 9 & 18.37 & \\
\hline III & 33 & 13.52 & 22 & 11.28 & 11 & 22.45 & \\
\hline IV & 100 & 40.92 & 78 & 40.00 & 22 & 44.90 & \\
\hline Elevated LDH (> $480 \mathrm{U} / \mathrm{L})$ & $151(212)$ & 71.22 & $113(167)$ & 67.66 & $37(44)$ & 84.09 & 0.0300 \\
\hline LDH (range) & $184-20000$ & - & $184-4000$ & - & $340-20000$ & - & 0.0003 \\
\hline ECOG performance status & 238 & - & 187 & - & 51 & - & 0.9800 \\
\hline 0 & 18 & 7.56 & 14 & 7.49 & 4 & 7.84 & \\
\hline 1 & 107 & 44.96 & 85 & 45.45 & 22 & 43.14 & \\
\hline 3 & 48 & 20.17 & 38 & 20.32 & 10 & 19.61 & \\
\hline 4 & 25 & 10.50 & 20 & 10.70 & 5 & 9.80 & \\
\hline B-symptoms & 67 (192) & 34.90 & $50(143)$ & 35.00 & $17(49)$ & 34.70 & 0.9730 \\
\hline Bone marrow involvement & $57(200)$ & 28.36 & $42(154)$ & 27.27 & $15(46)$ & 32.61 & 0.4820 \\
\hline Tumour site & & & & & & & 0.3530 \\
\hline Nodal & $127(249) \neq$ & 51.00 & $101(198) \ddagger$ & 51.01 & $26(51) \ddagger$ & 50.98 & \\
\hline Extranodal & $122(249)+$ & 49.00 & $97(198) \dagger$ & 48.99 & $25(51) \div$ & 49.02 & \\
\hline
\end{tabular}

$\dagger, \ln 44$ cases, gender was not recorded.

\$, Numbers in parentheses represent the total number of cases we have data on.

DLBCL, diffuse large B-cell lymphoma; B- symptoms, fever, night sweats and weight loss; LDH, lactate dehydrogenase; ECOG, Eastern Cooperative Oncology Group; HIV, human immunodeficiency virus.

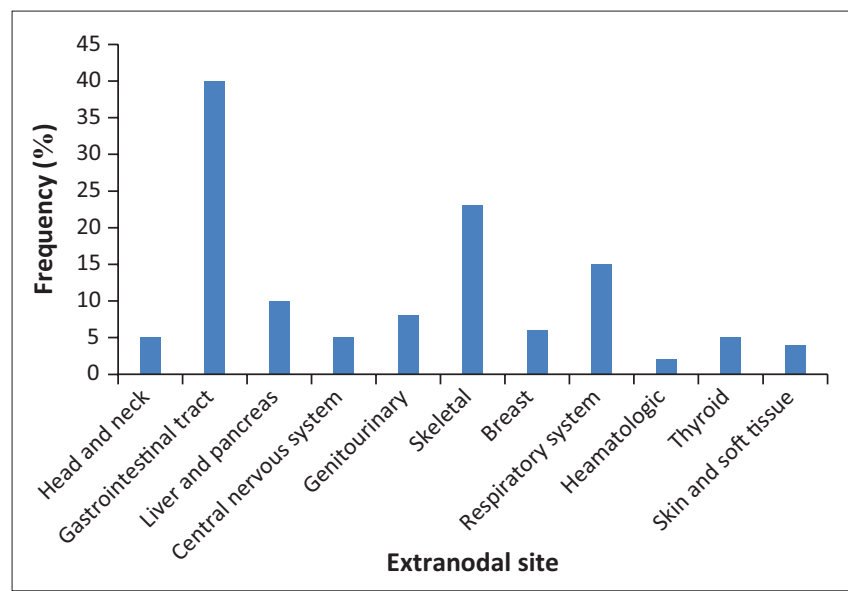

FIGURE 1: The frequency of the various extranodal sites in all diffuse large B-cell lymphoma cases. The gastrointestinal tract and skeletal sites were the most frequently observed.

the HIV-positive group, compared to the HIV-negative group ( $84 \%$ vs. $67 \%$ ) (Table 1$)$. In addition, the range of expression in the HIV-positive group was significantly higher (Table 1).

In $51 \%$ of all DLBCL cases, the site of disease was limited to lymph nodes (Table 1). Similar percentages for nodal involvement were observed for both HIV-negative and HIV-positive DLBCL cases (Table 1). In addition, no statistical differences in overall survival (OS) between nodal and EN lymphoma cases were observed for both HIV-negative and HIV-positive cases (supplementary figure). The most common EN sites were the GI tract $(40 / 122)$, bone $(23 / 122)$ and the respiratory system $(15 / 122)$ (Figure 1$)$. There were no differences in OS between the three most common EN sites in the HIV-negative group (Figure 3). The 10-year OS rates were $65.45 \%$ for the GI tract, $50.22 \%$ for the respiratory system and $23.98 \%$ for the skeletal site.

\section{Statistical analysis of oncology data}

Differences between the clinical and demographic parameters of HIV-negative and HIV-positive DLBCL were compared using the chi-square and the $t$-test. No statistically significant differences in gender, Ann Arbor stage, PS, B-symptoms, primary tumour site and BMi were observed (Table 1). The only statistically significant differences observed were for median age and elevated LDH levels. The HIV-positive group had a higher percentage of cases with elevated LDH levels (higher than $480 \mathrm{U} / \mathrm{L}$ ), compared to the HIV-negative group $(93 \%$ vs. $63 \%, p<0.05)$.

\section{Treatment outcome of diffuse large B-cell lymphoma patients}

In the HIV-positive group, 30 out of 54 (56\%) patients received five or more cycles of full-dose CHOP. The rest were treated with dose-reduced CHOP or palliative therapy. Some defaulted therapy. In comparison, 69 out of 205 (34\%) patients in the HIV-negative group did not complete five or more cycles of CHOP. The median survival for all DLBCL patients was 8.34 years (Figure 2) - 2.24 years for HIVpositive and 8.34 years for HIV-negative patients (Figure 2). There were 72 confirmed deaths in the HIV-negative group and 22 in the HIV-positive group. There were 131 cases lost to follow-up in the HIV-negative group and 28 cases in the HIV-positive group. 
The 5-year OS was 56\% versus $46 \%$ for HIV-negative versus HIV-positive DLBCL patients, respectively $(p=0.048)$ (Figure 2 and Table 3). Although not statistically significant, the HIV-negative patients had higher complete response (CR) rates, compared to HIV-positive patients ( $47 \%$ vs. $40 \%$ ) (Table 2). The relapse rate in the HIV-negative group was higher than the rate of the HIV-positive group (10\% vs. $8 \%$ )

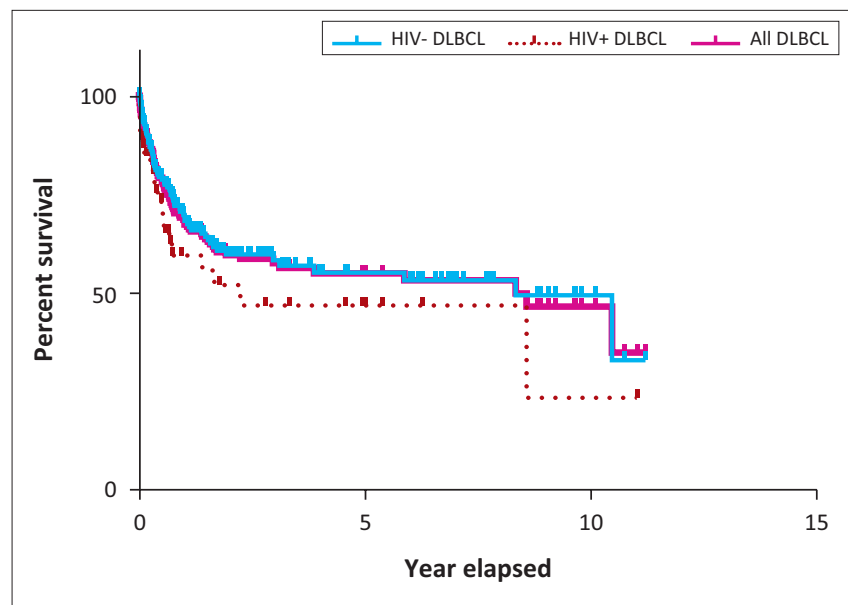

HIV, human immunodeficiency virus; DLBCL, diffuse large B-cell lymphoma.

FIGURE 2: Kaplan-Meier survival curve of HIV-infected (HIV+) and HIV-uninfected (HIV-) diffuse large B-cell lymphoma cases.

TABLE 2: Complete response and relapse rates of the diffuse large B-cell lymphoma patients treated at Groote Schuur Hospital.

\begin{tabular}{lccccc}
\hline DLBCL & & CR & Relapse (after CR) & No CR & Total \\
\hline HIV-neg & $N$ & 95 & 20 & 86 & 201 \\
& $\%$ & 47.26 & 9.95 & 42.79 & 100 \\
HIV-pos & $N$ & 21 & 4 & 27 & 52 \\
& $\%$ & 40.38 & 7.7 & 51.92 & 100 \\
Total & $N$ & 116 & $\mathbf{2 4}$ & $\mathbf{1 1 3}$ & $\mathbf{2 5 3}$ \\
& $\%$ & 45.85 & 9.49 & 44.66 & 100 \\
\hline
\end{tabular}

DLBCL, diffuse large B-cell lymphoma; CR, complete response; HIV-neg, human immunodeficiency virus-negative; HIV-pos, human immunodeficiency virus-positive.

TABLE 3: The surviving proportions of diffuse large B-cell lymphoma patients at 3-, 5- and 10-year intervals.

\begin{tabular}{lcc}
\hline Years elapsed & HIV- DLBCL (\%) & HIV+ DLBCL (\%) \\
\hline 3 & 58.40 & 46.30 \\
$5 *$ & 56.60 & 46.30 \\
10 & 50.70 & 23.10 \\
\hline
\end{tabular}

$*, P=0.0482$.

DLBCL, diffuse large B-cell lymphoma; HIV, human immunodeficiency virus.
(Table 2). There were too few patients who received rituximab to be able to assess its impact on survival.

\section{Prognostic factors affecting overall survival}

Linear regression was performed to determine the prognostic indicators affecting patient outcome. The clinical and demographic parameters were given codes for the analysis. The analysis was performed on all the DLBCL cases, irrespective of HIV status prior to analysing the two cohorts of the study. Advanced age, stage, BMi and female gender were associated with poor prognosis for DLBCL cases (Table 4). When considering the HIV status, the same factors were prognostic in HIV-negative cases with the inclusion of the primary EN tumour site (Table 4).

\section{Discussion}

This study determined the clinical and demographic differences between HIV-negative and HIV-positive DLBCL cases. The DLBCL cases diagnosed and treated at GSH were located using an NHLS list. The number of patients treated at GSH was lower than expected when considering the number of DLBCL cases diagnosed. Not all patients diagnosed at the NHLS Anatomical Pathology laboratory of GSH are treated at the GSH Department of Radiation Oncology. Some are treated at a secondary hospital in George (a small town in the Western Cape) and others may have demised prior to being referred for treatment. In addition, the SNOMED code used to create the list is not specific for DLBCL and includes large T-cell lymphomas. The SNOMED system used is not aligned to the current WHO classification of lymphomas. We observed a median age for DLBCL cases occurring at the early sixth decade (Table 1), thus confirming previous studies. 3,19,20,21 The lower median age at diagnosis for HIVpositive DLBCL patients has been previously reported and ranged in the fourth decade in South Africa ${ }^{15,22}$ and the fifth decade abroad. ${ }^{23}$

Our study observed a female predominance, in both HIVnegative and HIV-positive groups, which is contrary to the male predominance that was previously reported. ${ }^{24}$ This may be because of the 44 cases with no recorded gender, which

TABLE 4: The linear regression analysis of prognostic factors affecting overall survival.

\begin{tabular}{|c|c|c|c|c|c|c|c|c|c|}
\hline \multirow[t]{2}{*}{ Factor } & \multicolumn{3}{|c|}{ All DLBCL patients } & \multicolumn{3}{|c|}{ HIV- DLBCL patients } & \multicolumn{3}{|c|}{ HIV+ DLBCL patients } \\
\hline & $\boldsymbol{B}$ & SE of $B$ & $p$ & $B$ & SE of $B$ & $p$ & $\boldsymbol{B}$ & SE of $B$ & $p$ \\
\hline Age & 0.150 & 0.0615 & 0.020 & 0.170 & 0.0691 & 0.0014 & 0.11 & 0.14 & 0.44 \\
\hline Gender & -0.150 & 0.0667 & 0.030 & -0.200 & 0.0765 & 0.0098 & 0.01 & 0.14 & 0.95 \\
\hline Stage & 0.170 & 0.0632 & $<0.001$ & 0.160 & 0.0711 & 0.0300 & 0.20 & 0.14 & 0.18 \\
\hline BMI & -0.240 & 0.0690 & $<0.001$ & -0.230 & 0.0789 & 0.0040 & -0.26 & 0.14 & 0.07 \\
\hline EN lymphoma & 0.080 & 0.0600 & 0.230 & -0.140 & 0.0707 & 0.0400 & 0.13 & 0.14 & 0.36 \\
\hline LDH & 0.150 & 0.0404 & 0.038 & 0.178 & 0.0605 & 0.0340 & 0.211 & 0.089 & 0.196 \\
\hline Presence of B-symptoms & 0.020 & 0.0700 & 0.790 & 0.010 & 0.1000 & 0.9400 & -0.02 & 0.14 & 0.86 \\
\hline HIV status & 0.040 & 0.0600 & 0.490 & ND & ND & ND & ND & ND & ND \\
\hline CD4 count & -0.090 & 0.1400 & 0.530 & ND & ND & ND & 0.06 & 0.14 & 0.70 \\
\hline
\end{tabular}

$B$, regression coefficient; SE, standard error; ND, not determined; IPI, International Prognostic Index; DLBCL, diffuse large B-cell lymphoma; BMI, body mass index; EN, extranodal; B- symptoms, fever, night sweats and weight loss; CD4; LDH, lactate dehydrogenase; HIV, human immunodeficiency virus.

The HIV-positive cohort did not have significant prognostic indicators. 
could have skewed the data towards a female predominance. However, possible reasons for gender differences in cancer have been elucidated for other cancers, yet this has not been done for lymphoma. ${ }^{25}$ In addition, the increased number of females in the HIV-positive group may be because of relatively larger numbers of females that are infected with HIV in South Africa. ${ }^{26,27}$ This is in keeping with a similar study conducted previously in South Africa showing an overrepresentation of females. ${ }^{22}$

We did not observe any statistical difference in stage, PS and frequency of B-symptoms between the HIV-negative and HIVpositive DLBCL groups (Table 1). This is in contrast with a study conducted in a Spanish population, ${ }^{23}$ which showed that HIV-infected patients were more likely to have worse prognostic indicators (higher PS scores, frequent B-symptoms and a higher stage). The differences observed may be because of the poor socio-economic status impacting on patient survival. ${ }^{28}$

Our study observed that the HIV-positive group frequently had higher LDH levels that confirm other studies reporting the difference in LDH levels (Table 1). ${ }^{23,29,30}$ The LDH enzyme catalyses the conversion of pyruvate to lactate and is a key enzyme of glycolysis. It is elevated in many types of cancers and has been linked to tumour growth, maintenance and invasion. ${ }^{31}$ A disturbed cellular metabolism because of cancer and infectious conditions may trigger the release of high levels of LDH into the blood stream. ${ }^{32}$ In addition, HAART has also been shown to result in elevated LDH in HIV-positive individuals because of its role in the inflammatory response. ${ }^{33}$ Therefore, this parameter may be frequently elevated in the HIV-positive group because of HIV infection as well as HAART use.

The HIV-positive DLBCL group had significantly lower overall survival, thus affirming published data (Figure 2). ${ }^{15,23}$ However, the 3-year OS rate for HIV-positive DLBCL in our study was higher than the one published by De Witt (2013), in spite of the study population being from the same region. The reason for the differences observed may be the varying treatment regimens received by our patients, including palliative radiotherapy and chemotherapy, whereas the cohort used by De Witt received CHOP only. The CR rates were higher in the HIV-negative cohort confirming previously published data. ${ }^{23}$

We did not observe any statistically significant differences in the distribution of nodal and EN cases between the two DLBCL groups (Table 1). This is different from the study conducted by Pather et al. who found HIV-positive cases to be more likely to have EN tumours. ${ }^{34}$ The contradiction may be because of differences in sample size as well as the inclusion of plasmablastic lymphoma cases in their analysis. In addition, differences in the classification systems used to classify nodal and EN lymphomas may also result in contradictions. For example, some studies include the Waldeyer's ring in the nodal category, while others exclude this. ${ }^{4,21}$ This may lead to discrepancies in the frequency of nodal and EN cases. Our study confirms previous data, suggesting that the GI tract is the most common EN site. ${ }^{4}$ In addition, our study indicated that the EN tumour site was associated with worse outcome in the HIV-negative group, and this was also observed in previous studies. ${ }^{21}$ Our results indicated that skeletal or bone EN sites have a lower median survival in the HIV-negative group, although this was not significant (Figure 3). We could not determine the effect that each EN site had on the outcome because of low sample size in most groups, especially in the HIV-positive group. However, previous studies indicate that the GI tract and liver or pancreas demonstrated the worst outcome. ${ }^{21}$ A larger multicentre cohort may assist in determining the prognostic effect of each EN site in the South African population. The prognostic effect of EN tumours may lie in the genetic and molecular differences inherent between nodal and EN tumours. ${ }^{4,35}$ Extranodal lymphomas have frequent gains of chromosomal arms, 1p, 7p, 12q24.21-12q24.31, and loss of chromosome, 4, 6q and 18q22.3-23, while nodal lymphomas frequent $18 \mathrm{q}$ amplification and BCL2 protein overexpression. ${ }^{35}$

Our finding regarding age, gender, LDH, stage, bone and marrow involvement indicated that they were prognostic indicators for all DLBCL patients, including the HIVnegative cases (Table 2). The study by Klapper et al. showed that increased age was associated with poor prognosis. ${ }^{36}$ In addition, age, stage and EN sites are part of the IPI, ${ }^{37}$ highlighting their importance as prognostic markers. Bone marrow involvement has been previously identified to negatively affect overall survival. ${ }^{38}$ Our study reports that the female gender is associated with worse prognosis. This result is contrary to the studies performed in other parts of the world, which indicate that males have worse prognosis. ${ }^{24,39}$ The poor prognosis in females in our cohort may be because of the increased risk of anthracyclineinduced cardiotoxic side effects in females. ${ }^{40}$ It must be stressed that this audit was performed before the widespread availability of rituximab in the public-sector hospitals in South Africa. In addition, HIV treatment and adherence has

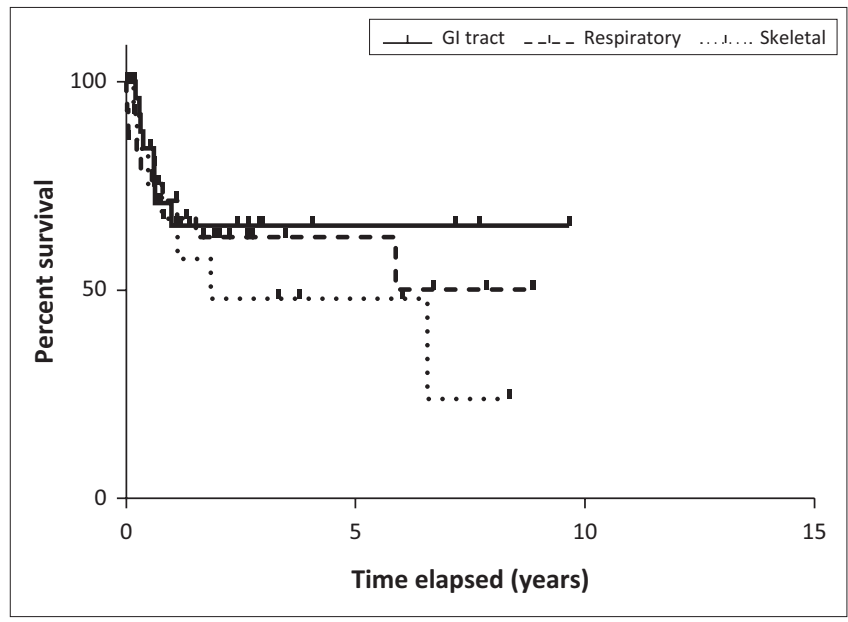

GI, gastrointestinal.

FIGURE 3: Kaplan-Meier graph comparing the overall survival of extranodal lymphoma patients presenting in gastrointestinal tract, and respiratory and skeletal sites in the human immunodeficiency virus-negative cohort. 
improved with the use of minimally cross-reactive fixeddose combination antiretroviral therapy. Rituximab has improved the outcome in HIV-positive patients to the extent that being HIV-positive is no longer a poor prognostic indicator, and survival is only affected by IPI. ${ }^{10,41,42,43}$

In summary, our study observed that HIV-negative and HIV-positive DLBCL patients have similar clinical features, but they differ in median age at diagnosis and frequency of elevated LDH levels. The HIV-positive DLBCL group was also shown to have poorer overall survival. Finally, age, gender, stage and $\mathrm{BMi}$ were found to be prognostic indicators for all DLBCL patients, irrespective of their HIV status. In addition, the presence of lymphoma in EN sites was also prognostic for the HIV-negative group.

\section{Acknowledgements}

The work presented in this article is adapted from the doctoral thesis submitted by P.S. Magangane at the University of Cape Town.

\section{Competing interests}

The authors have declared that no competing interests exist.

\section{Author's contributions}

P.S.M. collected and analysed the data. Z.M. collected the data. R.N. was the project leader. All the authors co-wrote the manuscript.

\section{Funding information}

This study was funded by the National Health Laboratory Services Research Trust, the National Research Foundation and the University of Cape Town.

\section{Data availability statement}

Data sharing is not applicable to this article, as no new data were created or analysed in this study.

\section{Disclaimer}

The views and opinions expressed in this article are those of the authors and do not necessarily reflect the official policy or position of any affiliated agency of the authors.

\section{References}

1. Zhou D, Xie W, Hu K, et al. Prognostic values of various clinical factors and genetic subtypes for diffuse large B-cell lymphoma patients: A retrospective analysis of 227 cases. Asian Pacific J Cancer Prev. 2013;14(2):929-934. https://doi. org/10.7314/apjcp.2013.14.2.929

2. Mey $U$, Hitz F, Lohri A, et al. Diagnosis and treatment of diffuse large B-cell lymphoma. Swiss Med Wkly. 2012;142(1):w13511. https://doi.org/10.4414/ smw.2012.13511

3. Hunt KE, Reichard KK. Diffuse large B-cell lymphoma. Arch Pathol Lab Med. 2008;132(1):118-124. https://doi.org/10.1043/1543-2165(2008)132[118:DLBL]2 $0 . \mathrm{CO} ; 2$

4. López-Guillermo A, Colomo L, Jiménez M, et al. Diffuse large B-cell lymphoma: Clinical and biological characterization and outcome according to the nodal or extranodal primary origin. J Clin Oncol. 2005;23(12):2797-2804. https://doi. org/10.1200/JCO.2005.07.155
5. Vishnu P, Aboulafia DM. AIDS-related non-Hodgkin's lymphoma in the era of highly active antiretroviral therapy. Adv Hematol. 2012;2012:485943. https://doi. org/10.1155/2012/485943

6. Shipp M. The international non-Hodgkins lymphoma prognostic factors. A predictive model for aggressive non-Hodgkin's lymphoma. N Engl J Med. 1993;329(14):987-994. https://doi.org/10.1056/NEJM199309303291402

7. Sehn LH, Berry B, Chhanabhai $M$, et al. The revised international prognostic index (R-IPI) is a better predictor of outcome than the standard IPI for patients with diffuse large B-cell lymphoma treated with R-CHOP. Blood. 2007;109(5):1857-1861. https://doi.org/10.1182/blood-2006-08-038257

8. Salles G, De Jong D, Xie W, et al. Prognostic significance of immunohistochemical biomarkers in diffuse large B-cell lymphoma: A study from the Lunenburg Lymphoma Biomarker Consortium. Blood. 2011;117(26):7070-7078. https://doi. org/10.1182/blood-2011-04-345256

9. Zhou Z, Sehn LH, Rademaker AW, et al. An enhanced international prognostic index (NCCN-IPI) for patients with diffuse large B-cell lymphoma treated in the rituximab era. Blood. 2014;123(6):837-843. https://doi.org/10.1182/blood2013-09-524108

10. Coutinho R, Pria AD, Gandhi S, et al. HIV status does not impair the outcome of patients diagnosed with diffuse large B-cell lymphoma treated with R-CHOP in the CART era. AIDS. 2014;28(5):689-697. https://doi.org/10.1097/QAD.0000000000000133

11. Barta SK, Xue X, Wang $D$, et al. A new prognostic score for AIDS-related lymphomas in the rituximab-era. Haematologica. 2014;99(11):1731-1737. https://doi.org/10. 3324/haematol.2014.111112

12. Wang C-C, Castillo JJ. Management of HIV-associated lymphomas. Med Health R I. 2011;94(1):4-6.

13. Patel $M$, Philip $V$, Omar $T$, et al. The impact of human immunodeficiency virus infection (HIV) on lymphoma in South Africa. J Cancer Ther. 2015;6(6):527-535.

14. Grogg KL, Miller RF, Dogan A. HIV infection and lymphoma. J Clin Pathol. 2007;60(12):1365-1372. https://doi.org/10.1136/jcp.2007.051953

15. De Witt P, Maartens DJ, Uldrick TS, Sissolak G. Treatment outcomes in AIDSrelated diffuse large B-cell lymphoma in the setting roll-out of combination antiretroviral therapy in South Africa. J Acquir Immune Defic Syndr. 2014;64(1): 66-73. https://doi.org/10.1097/QAl.0b013e3182a03e9b

16. Carroll V, Garzino-Demo A. HIV-associated lymphoma in the era of combination antiretroviral therapy: Shifting the immunological landscape. Pathog Dis. 2015;73(7):ftv044. https://doi.org/10.1093/femspd/ftv044

17. Gloghini A, Dolcetti R, Carbone A. Lymphomas occurring specifically in HIVinfected patients: From pathogenesis to pathology. Semin Cancer Biol. 2013;23(6):457-467. https://doi.org/10.1016/j.semcancer.2013.08.004

18. Møller MB, Pedersen NT. Diffuse large B-cell lymphoma: Clinical implications of extranodal versus nodal presentation - A population-based study of 1575 cases. $\mathrm{Br}$ Haematol. 2004;124(2):151-159. https://doi.org/10.1046/j.1365-2141.2003.04749.x

19. Bürgesser MV, Gualco G, Diller A, Natkunam Y, Bacchi CE. Clinicopathological features of aggressive B-cell lymphomas including B-cell lymphoma, unclassifiable, with features intermediate between diffuse large B-cell and Burkitt lymphomas: A study of 44 patients from Argentina. Ann Diagn Pathol. 2013;17(3):250-255. https://doi.org/10.1016/j.anndiagpath.2012.11.001

20. Flowers $\mathrm{CR}$, Shenoy PJ, Borate U, et al. Examining racial differences in diffuse large B-cell lymphoma presentation and survival. Leuk Lymphoma. 2013;54(2):268-276. https://doi.org/10.3109/10428194.2012.708751

21. Castillo JJ, Winer ES, Olszewski AJ. Sites of extranodal involvement are prognostic in patients with diffuse large B-cell lymphoma in the rituximab era: An analysis of
the surveillance, epidemiology and end results database. Am J Heamtol. the surveillance, epidemiology and end results databas
2014;89(3):310-314. https://doi.org/10.1002/ajh.23638

22. Wiggill TM, Mantina H, Willem P, Perner $Y$, Stevens WS. Changing pattern of lymphoma subgroups at a tertiary academic complex in a high-prevalence HIV setting: A South African perspective. I Acquir Immune Defic Syndr. 2011; 56(5):460-466. https://doi.org/10.1097/QAl.0b013e31820bb06a

23. Baptista JM, Garcia O, Morgades M, et al. HIV-infection impact on clinical Biological features and outcome of diffuse large B-cell lymphoma treated with R-CHOP in the combination antiretroviral therapy era. AIDS. 2015;29(7):811818. https://doi.org/10.1097/QAD.0000000000000624

24. Sarkozy C, Mounier N, Delmer A, et al. Impact of BMI and gender on outcomes in DLBCL patients treated with R-CHOP: A pooled study from the LYSA. Lymphoma. 2014;2014. Article ID 205215. https://doi.org/10.1155/2014/205215

25. Mester B, Nieters A, Deeg E, Elsner G, Becker N, Seidler A. Occupation and malignant lymphoma: A population based case control study in Germany. Occup Env Med. 2006;63(1):17-26. https://doi.org/10.1136/oem.2005.020453

26. Joint United Nations Programme on HIV/AIDS (UNAIDS). The gap report, Geneva, UNAIDS; 2015.

27. Shisana O, Rehle T, Simbayi L, et al. South African national HIV prevalence, incidence and behaviour survey, 2012. Cape Town: HSRC, 2012.

28. Tao L, Foran JM, Clarke CA, Gomez SL, Keegan THM. Socioeconomic disparities in mortality after diffuse large B-cell lymphoma in the modern treatment era. Blood. 2014;123(23):3553-3563. https://doi.org/10.1182/blood-2013-07-517110

29. Williams I, Churchill D. Management of advanced HIV disease with no other complications in women and in Africans. Int J Clin Pract. 2007;61(1):119-129. https://doi.org/10.1111/j.1742-1241.2006.01236.x

30. Lu R, Jiang $M$, Chen $Z$, et al. Lactate dehydrogenase 5 expression in non-Hodgkin lymphoma is associated with the induced hypoxia regulated protein and poor prognosis. PLoS One. 2013;8(9):e74853. https://doi.org/10.1371/journal.pone.0074853

31. Miao P, Sheng S, Sun X, Liu J, Huang G. Lactate dehydrogenase A in cancer: A promising target for diagnosis and therapy. IUBMB Life. 2013;65(11):904-910.
https://doi.org/10.1002/iub.1216 
32. Ramana KV, Rao R, Kandi S, Singh PA, Kumar VBP. Elevated activities of serum lactate dehydrogenase in human immunodeficiency virus sero-positive patients in
highly active antiretroviral therapy era. J Dr NTR Univ Heal Sci. 2013;2(3):162-166. highly active antiretroviral therapy era. J Dr
https://doi.org/10.4103/2277-8632.117180

33. Blanco F, García-Benayas T, José de la Cruz J, González-Lahoz J, Soriano V. First-line therapy and mitochondrial damage: Different nucleosides, different findings. HIV Clin Trials. 2016;4(1):11-19. https://doi.org/10.1310/HF1J-3P6K-1K9H-AGPY

34. Pather S, Mohamed Z, McLeod H, Pillay K. Large cell lymphoma: Correlation of HIV status and prognosis with differentiation profiles assessed by immunophenotyping. Pathol Oncol Res. 2013;19(4):695-705.https:/

35. Al-Humood SA, Al-Qallaf AS, Alshemmari SH, et al. Genotypic and phenotypic differences between nodal and extranodal diffuse large B-cell lymphomas. J Histochem Cytochem. 2011;59(10):918-931. https://doi.org/10.1369/0022155411417309

36. Klapper W, Kreuz M, Kohler CW, et al. Patient age at diagnosis is associated with the molecular characteristics of diffuse large B-cell lymphoma. Blood. 2012;119(8):1882-1887. https://doi.org/10.1182/blood-2011-10-388470

37. Shipp M, Harrington D, Anderson J, Armitage J, Bonadona G, Brittinger G. A predictive model for aggressive non-Hodgkin's lymphoma: The international nonHodgkin's lymphoma prognostic factors project. N EnglJ Med. 1993;329(14):987-994 https://doi.org/10.1056/NEJM199309303291402
38. Shim H, Oh J, Park SH, et al. Prognostic impact of concordant and discordant cytomorphology of bone marrow involvement in patients with diffuse large B-cell cytomorphology of bone marrow involvement in patients with difuse large B-cell org/10.1136/jclinpath-2012-201158

39. Yıldırım M, Kaya V, Demirpençe Ö, Paydaş S. Systematic review/meta-analysis the role of gender in patients with diffuse large B cell lymphoma treated with rituximabcontaining regimens: A meta-analysis. Arch Med Sci. 2015;11(4):708-714.

40. Volkova M, Russell R. Anthracycline cardiotoxicity: Prevalence, pathogenesis and treatment. Curr Cardiol Rev. 2011;7(4):214-220. https://doi.org/10.2174/ 157340311799960645

41. Besson C, Lancar R, Prevot S, et al. Outcomes for HIV-associated diffuse large B-cell lymphoma in the modern combined antiretroviral therapy era. AIDS. 2017;31(18):2493-2501. https://doi.org/10.1097/QAD.0000000000001652

42. Barta SK, Samuel MS, Xue X, et al. Changes in the influence of lymphoma- and HIV-specific factors on outcomes in AIDS-related non-Hodgkin lymphoma. Ann Oncol. 2015;26(5):958-966. https://doi.org/10.1093/annonc/mdv036

43. Cingolani A, Lepri AC, Teofili L, et al. Survival and predictors of death in people with HIV-associated lymphoma compared to those with a diagnosis of lymphoma in general population. PLoS One. 2017;12(10):1-15. https://doi.org/10.1371/ journal.pone.0186549 